Article

\title{
Screening of Heteroaromatic Scaffolds against Cystathionine Beta-Synthase Enables Identification of Substituted Pyrazolo[3,4-c]Pyridines as Potent and Selective Orthosteric Inhibitors
}

\author{
Anna-Maria Fantel ${ }^{1}$, Vassilios Myrianthopoulos ${ }^{1} \oplus$, Anastasios Georgoulis ${ }^{2}$, \\ Nikolaos Lougiakis ${ }^{1}$, Iliana Zantza ${ }^{1}$, George Lamprinidis ${ }^{1}{ }^{1}$, Fiona Augsburger ${ }^{3}{ }^{(0)}$, \\ Panagiotis Marakos ${ }^{1}$, Constantinos E. Vorgias ${ }^{2}$, Csaba Szabo ${ }^{3}{ }^{\mathbb{D}}$, Nicole Pouli ${ }^{1}$, \\ Andreas Papapetropoulos ${ }^{1}$ (D) and Emmanuel Mikros $1,4, *$ (D) \\ 1 Department of Pharmacy, National and Kapodistrian University of Athens, \\ 15774 Panepistimiopolis, Zografou, Greece; anmafantel@pharm.uoa.gr (A.-M.F.); \\ vmyriant@pharm.uoa.gr (V.M.); nlougiak@pharm.uoa.gr (N.L.); izantza@pharm.uoa.gr (I.Z.); \\ lamprinidis@pharm.uoa.gr (G.L.); marakos@pharm.uoa.gr (P.M.); pouli@pharm.uoa.gr (N.P.); \\ apapapet@pharm.uoa.gr (A.P.) \\ 2 Department of Biology, National and Kapodistrian University of Athens, \\ 15701 Panepistimiopolis, Zografou, Greece; tgeorgoulis@med.uoa.gr (A.G.); cvorgias@biol.uoa.gr (C.E.V.) \\ 3 Pharmacology, Section of Medicine, University of Fribourg, Ch. du Musée 18, 1700 Fribourg, Switzerland; \\ fiona.augsburger@unifr.ch (F.A.); csaba.szabo@unifr.ch (C.S.) \\ 4 PharmaInformatics Unit, "Athena" Research and Innovation Center, Artemidos 6, 15125 Maroussi, Greece \\ * Correspondence: mikros@pharm.uoa.gr; Tel.: +30-2107274813
}

Academic Editor: Jorge A.R. Salvador

Received: 30 June 2020; Accepted: 15 August 2020; Published: 16 August 2020

check for updates

\begin{abstract}
Cystathionine $\beta$-synthase (CBS) is a key enzyme in the production of the signaling molecule hydrogen sulfide, deregulation of which is known to contribute to a range of serious pathological states. Involvement of hydrogen sulfide in pathways of paramount importance for cellular homeostasis renders CBS a promising drug target. An in-house focused library of heteroaromatic compounds was screened for CBS modulators by the methylene blue assay and a pyrazolopyridine derivative with a promising CBS inhibitory potential was discovered. The compound activity was readily comparable to the most potent CBS inhibitor currently known, aminoacetic acid, while a promising specificity over the related cystathionine $\gamma$-lyase was identified. To rule out any possibility that the inhibitor may bind the enzyme regulatory domain due to its high structural similarity with cofactor s-adenosylmethionine, differential scanning fluorimetry was employed. A sub-scaffold search guided follow-up screening of related compounds, providing preliminary structure-activity relationships with respect to requisites for efficient CBS inhibition by this group of heterocycles. Subsequently, a hypothesis regarding the exact binding mode of the inhibitor was devised on the basis of the available structure-activity relationships (SAR) and a deep neural networks analysis and further supported by induced-fit docking calculations.
\end{abstract}

Keywords: cystathionine $\beta$-synthase; hydrogen sulfide; docking-scoring calculations; 7-azido-4methylcoumarin assay; pyrazolo[3,4-c]pyridine; Sitemap algorithm; back-propagation DNN; thermal shift assay; Bateman module

\section{Introduction}

Endogenously generated hydrogen sulfide, $\mathrm{H}_{2} \mathrm{~S}$, is a signaling molecule of pivotal importance and its biosynthesis in mammalian cells is facilitated by three enzymes, cystathionine $\beta$-synthase (CBS), cystathionine 
$\gamma$-lyase (CSE), and 3-mercaptopyruvate sulfurtransferase (3-MST) [1-4]. Cystathionine $\beta$-synthase, or CBS, is the first enzyme of the transsulfuration pathway in which the potentially toxic metabolite homocysteine is converted to cysteine [4]. Among others, human CBS catalyzes the condensation of serine and homocysteine to cystathionine and also utilizes cysteine as a substrate to yield $\mathrm{H}_{2} \mathrm{~S} . \mathrm{H}_{2} \mathrm{~S}$ is considered as an important biological mediator in a similar fashion to nitric oxide (NO) and carbon monoxide (CO) and CBS is responsible for $20 \%-75 \%$ of total $\mathrm{H}_{2} \mathrm{~S}$ production and, more specifically, up to $95 \%$ of its production in the brain [5]. The enzyme is located in the central nervous system as well as in other tissues (cardiovascular and gastrointestinal). CBS is regarded as a highly attractive drug target, as the development of potent and selective inhibitors may offer important therapeutic traits for a series of pathological states where $\mathrm{H}_{2} \mathrm{~S}$ signaling has a key role [6-11]. CBS overexpression has been reported in patients with Down syndrome, and leads to perturbation of $\mathrm{H}_{2} \mathrm{~S}$ levels in the human body [12,13]. Interestingly, the CBS gene is located on chromosome 21, the (complete or partial) trisomy which is the genetic basis of the Down phenotype [14,15]. Inhibition of enzymatic activity in these cases can prevent chronic exposure of Down syndrome patients to $\mathrm{H}_{2} \mathrm{~S}$ and potential prevention of related neurological deficits $[16,17]$. Furthermore, CBS up-regulation has been detected in cancer cells including colon cancer, ovarian cancer and lung cancer, amongst others [2,8,18-21]. Under these conditions, tumor growth is facilitated through stimulation of cellular bioenergetics, cell proliferation and angiogenesis [2,22,23].

In terms of structure, CBS is a unique heme-containing pyridoxal $5^{\prime}$-phosphate (PLP)-dependent enzyme that is allosterically activated by s-adenosylmethionine (AdoMet or SAM) [24,25]. The full-length human CBS is a homotetramer consisting by $63 \mathrm{kDa}$ subunits, with each subunit comprising 551 residues [26]. CBS adopts a three-domain structure encompassing an N-terminal heme-binding domain, a central catalytic domain (PLP cavity) which is accessible only via a narrow channel, and a smaller c-terminal allosteric regulatory domain (CBS motif, Bateman module) [27,28]. The cofactor PLP is deeply buried in a cleft between the $\mathrm{N}$ - and the c-terminal domains adjacent to the active site. On the other hand, the heme binding site is located $20 \AA$ away from the active site. Although heme does not contribute to catalysis, it is believed to contribute to redox regulation of CBS. The enzyme regulatory domain is responsible for interaction with SAM. When SAM binds to this domain, it causes allosteric activation of CBS [21,29-31]. In mammals, the catalytic activity of CBS is increased up to 5-fold by allosteric SAM binding. In its functional form, CBS is believed to form a domain-swapped dimer where the C-terminal regulatory domain of one subunit is atop the N-terminal catalytic domain of the other (protein data bank code: 1JBQ) [24,32]. The domains of each subunit are reoriented upon SAM binding, leading to the aforementioned five-fold increase in catalytic activity.

A series of different scaffolds showing a promising inhibitory potential against CBS have been reported so far, with many of them being structurally unrelated synthetic molecules or natural products including flavonoids, coumarins and marine metabolites [2,33-36]. Yet, the most potent CBS inhibitor is a remarkably simple molecule, aminoacetic acid (AOAA), believed to react with PLP toward the formation of a new external aldimine $[3,28,37]$. However, AOAA is not selective for CBS, as it also inhibits CSE and interacts with other PLP-dependent enzymes as well [9]. Such a simple organic molecule could marginally be considered as a tractable lead for drug development. In this direction, exploring the available chemical space with the objective to discover new scaffolds that can act as promising leads for achieving potent and selective CBS is deemed a highly interesting screening endeavor [38]. The present study describes the evaluation of a unique small molecule library particularly rich in heterocyclic drug-like compounds, the discovery of a pyrazolopyridine derivative as a new selective CBS inhibitor and the elucidation of its inhibitory mode of action. The main results are derived from a series of orthogonal biochemical and biophysical assays and additional support is offered by theoretical approaches, including artificial intelligence modeling and molecular simulations. 


\section{Results and Discussion}

\subsection{Rationale and Compound Selection}

While there is no determined cocrystal structure of CBS with any of the published inhibitors, the available crystal structures and previous screening attempts regarding CBS have offered adequate structural data to support the notion that the protein could be characterized as a druggable target. This is true regardless of the relatively low hit rates and weak-to-medium inhibitory activities that have been so far recorded by the aforementioned screening endeavors against CBS. Though functional CBS comprises a complicated quaternary structure bound to several co-factors by means of their corresponding binding sites, the capacity of efficient ligand binding is deemed as particularly promising as to the active site of the enzyme, which comprises a topologically sound cavity for competitive inhibition by drug-like small molecule binding [10]. This was verified by a druggability analysis of the enzyme active site by implementing the Sitemap algorithm (Schrödinger LLC, New York, NY, USA, 2020). The algorithm characterizes binding sites in terms of structural and geometrical features affecting the affinity of potential small molecule binders. Such features are solvent exposure, degree of protein enclosure, hydrophobicity and hydrophilicity, as well as hydrogen bond capacity. Sitemap derives druggability scores (SiteScore and the variant Dscore), where a SiteScore above 0.8 indicates a druggable site and a value equal or higher than 1 denotes a particularly promising pocket. The analysis afforded a high score (SiteScore: 1.012; Dscore: 0.973), suggesting a predominantly promising cavity and further strengthening the hypothesis that, apart from molecules the size of the natural substrates, the enzyme might also interact with larger molecules that could hence function as modulators. In this direction, a focused compound collection was devised and a screening campaign was undertaken, aiming at the discovery of orthosteric CBS inhibitors. The collection was assembled from the in-house repository of the Pharmacy department of National and Kapodistrian University of Athens (NKUA). The NKUA repository (approximately 2000 entries) is a proprietary compound library assembled and enriched over the last years by synthetic molecules, natural products and semi-synthetic analogues derived from a number of phytochemical and synthetic projects. The library is characterized by high structural originality, as most of its components are natural products isolated from biodiversity hot-spots and their related semisynthetic analogues. In the present study, the objective was to sample the variety of heterocyclic scaffolds that are present in the abovementioned repository at the most efficient and timely fashion. The selection was mainly focused in choosing a representative ensemble of nitrogen-containing heteroaromatic scaffolds that could mimic the natural rings of purine or pyrimidine. Such systems comprise the main core of the repository and, most importantly, fall under regions of chemical space that are widely accepted as highly promising in terms of biological activity and privileged structural character. A number of diverse synthetic heterocycles that could be viewed as purine isosteres were considered, including derivatives that possess a central pyrazolopyridine, pyrrolopyridine, pyrazolopyrimidine, pyrrolopyrimidine, pyrazolopyrazole, pyrazinopyridine and pyrazolopyridazine scaffold (Figure 1A). The collection comprised $~ 600$ molecules of high originality. To achieve higher diversity and increase the success rate, this in-house collection was further enhanced by the addition of top-ranked compounds originating from the National Cancer Institute (NCI) Repository and selected by means of virtual screening. To this end, in silico screening based on rigid docking of the NCI Repository was performed as a part of the current CBS inhibitor development effort. The virtual screen utilized our previously developed model [10] (1JBQ crystal structure of CBS) and Glide (Glide SP algorithm, Schrödinger LLC, New York, NY, USA, 2020) [39-41]. In this instance, the absence of any inhibitor-CBS co-crystal structure mandates for manual creation of the docking grid (please see Materials section). The 80 compounds which ranked higher in terms of the GScore scoring function were selected from the NCI Repository and ordered. The final collection (NKUA repository and NCI subset) was characterized by a highly satisfactory degree of drug likeness (Figure 1B), thus enabling efficient exploration of the bioactivity landscape of N-containing heterocycles (analyzed by Canvas, Schrödinger LLC, New York, NY, USA, 2020) [42,43]. More specifically, the majority of the compounds 
were found to be in overall good compliance with the Rule-of-Five structural features (Figure 1B). As to the structural diversity of the collection, a considerable variety in the side chain decorations and substitution motifs was evident in the number of rings, with $88 \%$ of compounds carrying at least one additional ring system apart from the two-ring heteroaromatic core of purine and 1-ring of pyrimidine, respectively.

A<smiles>[R11]n1cnc2c(=O)[nH]ccc21</smiles><smiles>[R2]c1cc([R])c2[nH]nc([R1])c2n1</smiles><smiles>[R1]c1n[nH]c2c(=O)cc[nH]c12</smiles><smiles>[R2]c1cc2c([R])nn([R1])c2c(Br)n1</smiles><smiles>[R3]c1nncc2c1c([R3])nn2[R2]</smiles><smiles>[R1]c1nn([R1])c2c([R3])nncc12</smiles><smiles>[R1]c1cn([R1])c2c([R3])nccc12</smiles><smiles>[R]c1ncnc2c(Br)cn([R3])c12</smiles><smiles>[R3]c1nn([R2])c2c([R9])ncnc12</smiles><smiles>[R3]c1cc2c(nc1[R3])nc([R1])n2[R2]</smiles><smiles>[R2]c1cc(=O)c2cnn([R1])c2[nH]1</smiles><smiles>[R2]c1cc2cn([R1])nc2c([R3])n1</smiles>

\section{B}
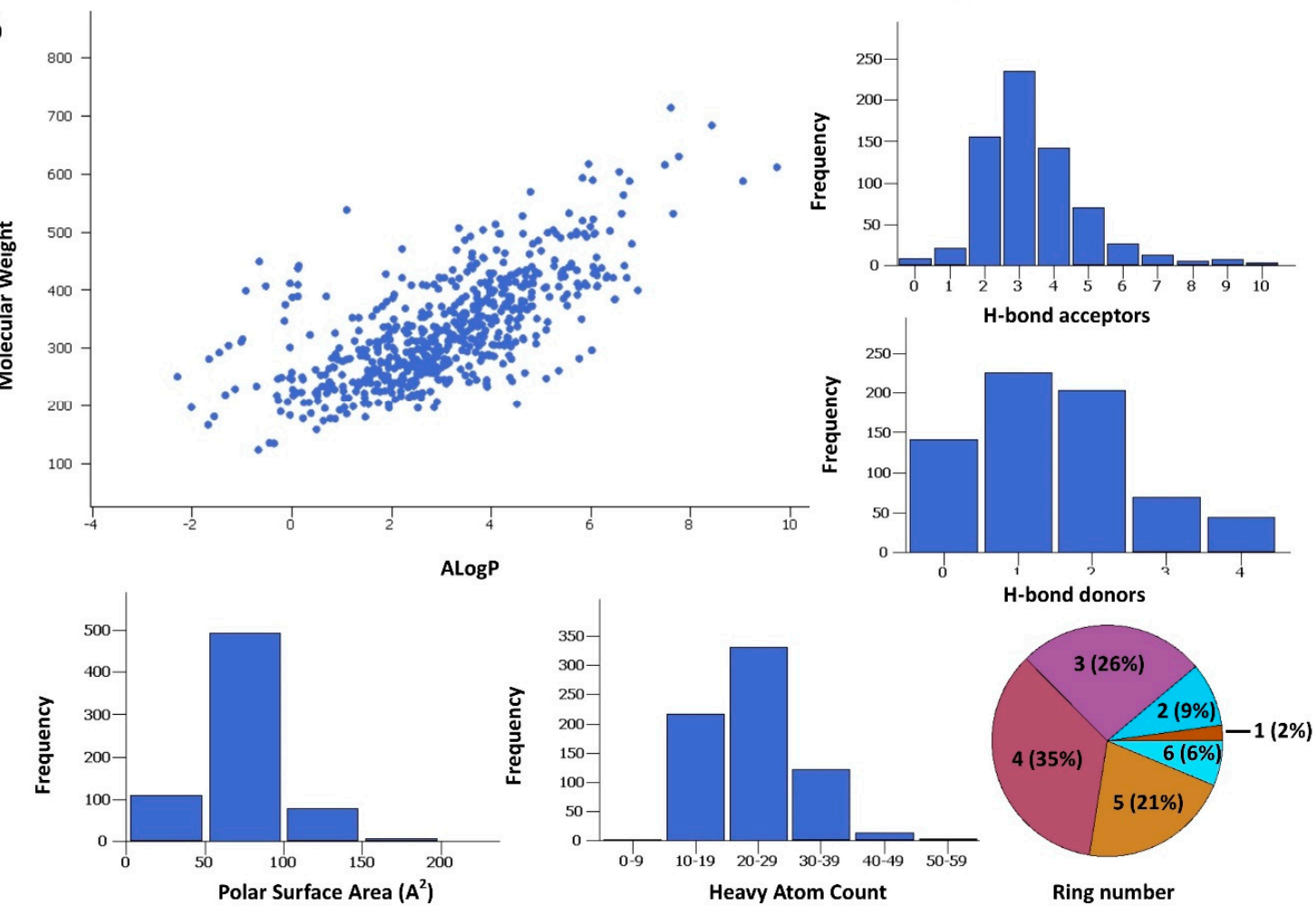

Figure 1. (A) The various substituted heteroaromatic scaffolds comprising the screened collection and the pyrazolo[3,4-c]pyridine core identified as a potent cystathionine $\beta$-synthase (CBS) inhibitor (inset denoted by a red cross). (B) Graphical evaluation of the collection drug-likeness in terms of key parameters related with the Rule-of-Five characteristics. 


\subsection{Protein Expression and In Vitro Evaluations}

Expression and purification of CBS have been described as complicated because of the strong tendency of the enzyme to aggregate [44-47]. In the present study, the protein was expressed and purified as described earlier, whereas specific modifications of the isolation procedures were undertaken as a means to improve both yield and purity of the enzyme. An expression system of the full-length human CBS was constructed and human CBS was expressed as a glutathione S-transferase (GST)-fusion protein [48]. A three-step purification workflow was organized, first by using affinity chromatography (GSTrap FF column), then by changing buffer and pooling high concentration samples into an anion exchange column (Q Sepharose) and, finally, by gel filtration. Consequently, almost $7.5 \mathrm{mg}$ of highly pure full-length active human CBS were obtained from $1 \mathrm{~L}$ of E. coli overnight culture. As a means to rule out any possibility that the identified hits could interact with the regulatory domain of CBS due to their structural resemblance with SAM (see discussion Section 2.3), the aforementioned domain was also expressed and purified accordingly. The total collection of the in-house heterocyclic structures ( 600 molecules) merged with the top-ranked NCI compounds (80 molecules) were evaluated in vitro for their CBS inhibitory potency.

Several experimental settings, either biochemical or biophysical, have been described for assessing the inhibitory potential of small molecules against CBS. Among them, the methylene blue assay is considered as one of the most robust methods available [49-51]. In the present study, enzymatic activity of the CBS fusion protein was measured by the ability to produce $\mathrm{H}_{2} \mathrm{~S}$ in a reaction employing $\mathrm{L}$-cysteine and homocysteine substrates. Quantification of $\mathrm{H}_{2} \mathrm{~S}$ was performed by using a standard curve and a $\mathrm{H}_{2} \mathrm{~S}$ donor. To confirm the adequate complexation of PLP within the protein during the purification process, the assay was performed in the presence and absence of $0.01 \mathrm{mM}$ PLP. In this study, to identify inhibitors, a quick first screening step was performed at a single inhibitor concentration of $50 \mu \mathrm{M}$ and compounds that afforded higher than 30\% CBS inhibition were further validated by additional assays and structurally analyzed. As expected, a moderate hit rate was determined by the screen, whereas several molecules emerged as CBS activators (Figure 2A). However, among the assayed molecules, the pyrazolopyridine derivative 1 was shown to be the most efficacious inhibitor. This specific molecule was previously synthesized in our lab as a potential inhibitor of angiogenesis [52]. In this molecule, the central pyrazolo[3,4-c]pyridine core is substituted by three functional groups which are present in many bioactive analogues, namely a $\mathrm{N}^{1}-4$-methoxybenzyl group attached to the pyrazole ring together with a 4-methylpiperazin-1-yl group and a 4-(4-methyl-piperazin-1-yl)phenylamino group connected to the nucleus (Figure 2B). To confirm the biological activity of the newly discovered pyrazolopyridine hit, the $\mathrm{IC}_{50}$ value of the inhibitor was determined and directly compared with that of AOAA, calculated in an identical setting. Notably, the dose-response curves were constructed in the presence of $1 \mathrm{mM}$ of L-cysteine and $1 \mathrm{mM}$ homocysteine. The $\mathrm{IC}_{50}$ value of 1 was $11 \mu \mathrm{M}$, whereas the corresponding value of AOAA was $8.5 \mu \mathrm{M}$ (Figure 2B). Of interest, when the new inhibitor 1 was tested against the related $\mathrm{H}_{2}$ S-producing enzyme CSE, it was found to possess considerably lower inhibitory activity (Figure 2C). The pyrazolopyridine inhibitor was tested against GST-CSE in three different concentrations in the presence of $1 \mathrm{mM}$ L-cysteine and $0.01 \mathrm{mM}$ PLP, resulting in no significant inhibitory effect.

For validating the most potent hit identified through the primary screen and rule out any possibility of undesirable interferences with the assay conditions leading to a false positive result, a parallel setting for $\mathrm{H}_{2} \mathrm{~S}$ detection by the use of 7-azido-4-methylcoumarin (AzMC) was opted for [53]. The inhibitory effect of 1 on CBS was confirmed with this $\mathrm{H}_{2} \mathrm{~S}$ detection method as well, although the $\mathrm{IC}_{50}$ value of $\mathbf{1}$ against CBS by the AzMC assay was determined at $103 \mu \mathrm{M}$. This difference likely reflects intrinsic methodological variations between the two assays that turn to be critical when the assayed compounds are ionized with $\mathrm{pKa}$ values in very close range to the $\mathrm{pH}$ of each setting ( $\mathrm{pH}$ values: 8.2 for methylene blue; 8 for AzMC assay). 


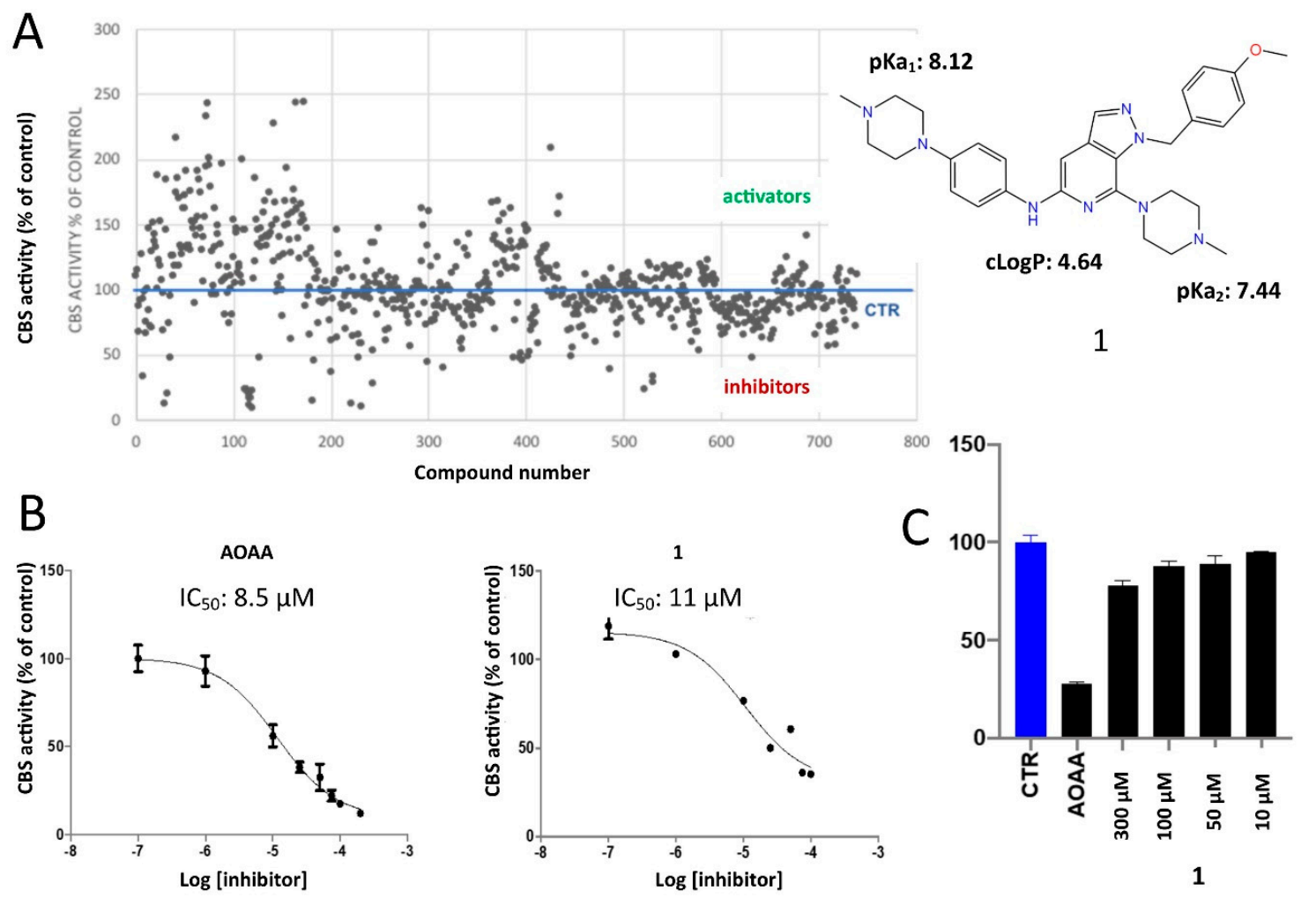

Figure 2. (A) A scatter plot summarizing obtained results from the single concentration screen against CBS. (B) The dose-response curves of $\mathbf{1}$ and AOAA show that the inhibitory activity of the pyrazolo[3,4-c]pyridine analogue is comparable to the most potent known CBS inhibitor, aminooxyacetic acid. (C) Evaluation of inhibitory potential of $\mathbf{1}$ against the related enzyme involved in $\mathrm{H}_{2} \mathrm{~S}$ production cystathionine $\gamma$-lyase (CSE), showing specificity of $\mathbf{1}$ toward CBS as compared to AOAA.

\subsection{Differential Scanning Fluorimetry}

Even though the whole screening strategy aimed at discovering ligands that target the active site of CBS, the non-negligible resemblance of $\mathbf{1}$ with the regulatory domain co-factor SAM in terms of their heterocyclic scaffolds prompted the exploration of the possibility that the identified hit inhibits CBS via allosteric binding. To address this issue, differential scanning fluorimetry experiments were undertaken as a way to rule out the possibility for binding interactions between $\mathbf{1}$ and the regulatory domain of CBS (CBS-RD) [54]. The thermal melt results unambiguously reproduced the previously reported extensive stabilization that cofactor binding offers to the protein, with $\Delta T_{m}$ values showing a dose-response increase in biologically relevant concentrations of SAM $\left(+2.98{ }^{\circ} \mathrm{C}, 100 \mu \mathrm{M}\right.$ SAM; $+12.43^{\circ} \mathrm{C}, 1 \mathrm{mM}$ SAM; Figure $3 \mathrm{~A}$ ), but failed to show a statistically significant shift for two different concentrations of $\mathbf{1}(10 \mu \mathrm{M}$ and $15 \mu \mathrm{M}$; Figure 3B), whereas addition of both SAM and 1 resulted in melting sigmoidals and respective $\Delta T_{m}$ values that were highly similar to the corresponding of the SAM/CBS-RD system $\left(+3.62^{\circ} \mathrm{C}, 100 \mu \mathrm{M} \mathrm{SAM}, 10 \mu \mathrm{M} \mathrm{1}\right.$; $+11.94{ }^{\circ} \mathrm{C}, 1 \mathrm{mM} \mathrm{SAM}, 15 \mu \mathrm{M} 1$; Figure $\left.3 \mathrm{C}\right)$ [30]. The lack of stabilization upon thermal denaturation of either CBS-RD or the SAM/CBS-RD complex in the presence of $\mathbf{1}$ was a clear indication that no significant binding occurs between the inhibitor and the regulatory component of the enzyme, thus providing validity to the suggestion that $\mathbf{1}$ is an orthosteric CBS inhibitor. 


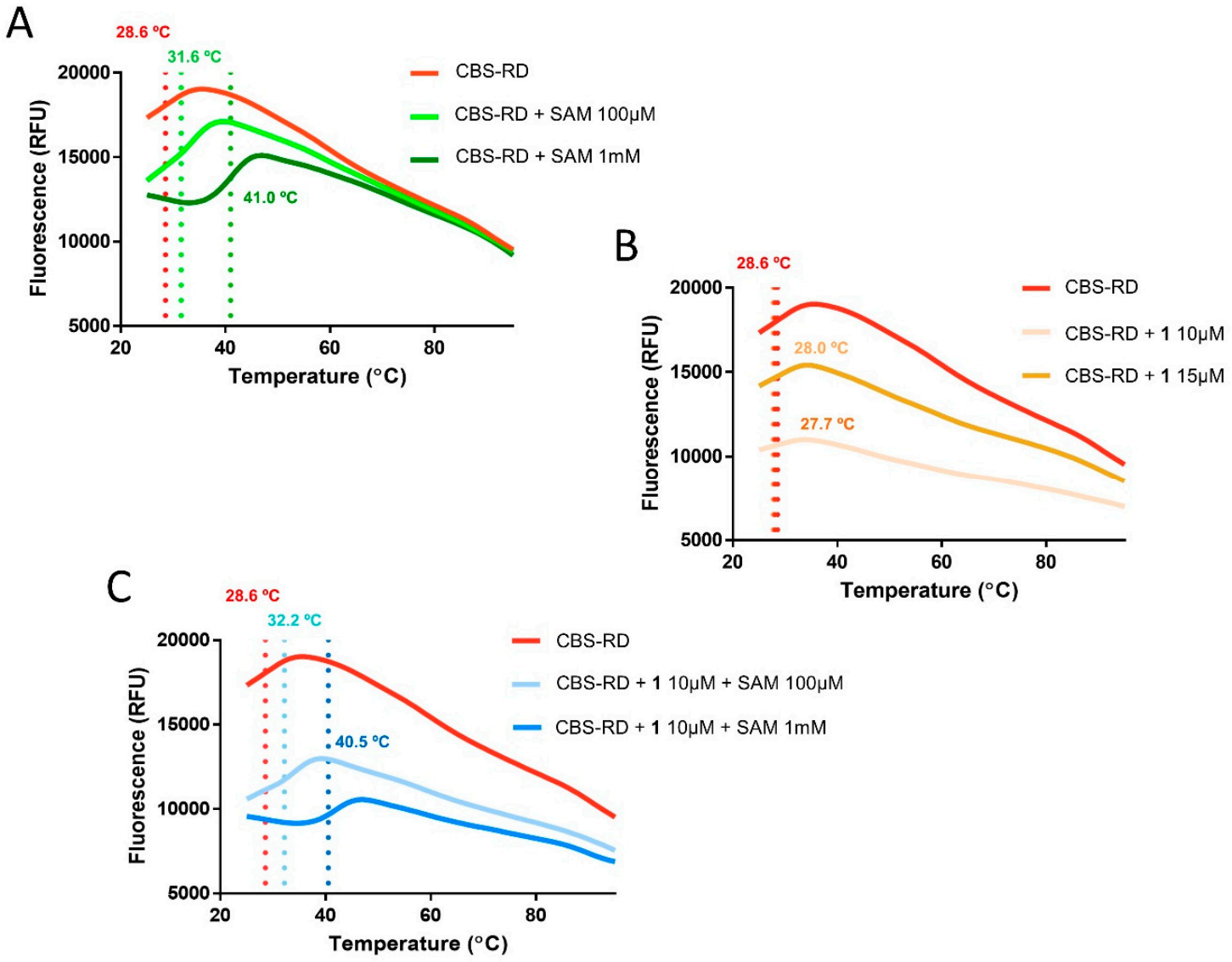

Figure 3. Differential scanning fluorimetry was implemented to identify a possible binding interaction of the inhibitor 1 with the regulatory domain of CBS (CBS-RD). A series of representative melting curves as those shown above, suggest that 1 does not bind CBS-RD. (A) Addition of the cofactor s-adenosylmethionine (SAM) $\left(100 \mu \mathrm{M}\right.$, light green, $T_{m}: 31.6^{\circ} \mathrm{C} ; 1 \mathrm{mM}$, dark green, $\left.T_{m}: 41.0^{\circ} \mathrm{C}\right)$ results in a dose-response stabilization effect on CBS-RD as compared to the apoprotein (red, $T_{m}: 28.6{ }^{\circ} \mathrm{C}$ ). (B) In contrast, no stabilization is monitored by increasing concentrations of $\mathbf{1}\left(10 \mu \mathrm{M}\right.$, light brown, $T_{m}$ : $28.0^{\circ} \mathrm{C} ; 15 \mu \mathrm{M}$, dark brown, $\left.T_{m}: 27.7^{\circ} \mathrm{C}\right)$. (C) Co-administration of SAM and $\mathbf{1}(100 \mu \mathrm{M} \mathrm{SAM}, 10 \mu \mathrm{M}$ 1, light blue, $T_{m}: 32.2{ }^{\circ} \mathrm{C} ; 1 \mathrm{mM} \mathrm{SAM}, 10 \mu \mathrm{M} \mathrm{1}$, dark blue, $T_{m}: 40.5^{\circ} \mathrm{C}$ ) results in a stabilization and response that are practically identical to the case where only SAM is bound to CBS-RD, showing that no binding or any kind of cooperativity takes place between $\mathbf{1}$ and the SAM-protein complex.

\subsection{Structure-Activity Relationships, Neural Networks Modeling and Theoretical Simulations}

As a means to explore the structure-activity relationships around the newly discovered CBS inhibitory core more thoroughly, a sub-scaffold search was performed and seven derivatives showing high similarity to 1 were recovered from the in-house repository and successively screened (Table 1 ). Derivatives 2, 3, 4 and 8 showed moderate to weak enzyme inhibitory activity when assayed at 100 $\mu \mathrm{M}$ and a dose-dependent biological response, whereas analogues 5,6 and 7 possessing an aromatic amino substituent at R1 were not active even at high concentrations (Table 1). Although none of those analogues showed an improved activity compared to $\mathbf{1}$, the results provided preliminary yet interesting structure-activity relationships that were subsequently used in combination with theoretical simulations to suggest a hypothesis as to the structural basis of CBS inhibition by the aforementioned pyrazolopyridine inhibitors. Minor structural modifications were found to be of major importance for the observed biological activity, as in the case of analogue 2 . This is the second most active inhibitor, showing though a considerable decrease of inhibitory potency from $70 \%$ to only $30 \%$ at $100 \mu \mathrm{M}$ that follows a simple removal of the 4-methyl group of the piperazine substituent R1 as compared to 1 . The decrease in activity of $\mathbf{2}$ was thought of as an indication that the ionization and total charge of 
studied compounds are factors of key importance for CBS inhibition. More specifically, the structural perturbation involving the transition from $\mathbf{1}$ to 2 is expected to confer a critical shift not only to the ionization potential of the two compounds, with the basic character of the less potent inhibitor being considerably increased, but also to the trend of protonations given that the emergence of a secondary amine at R1 of 2 reverses the relative order by which the two 4-piperazinyl nitrogens of positions $\mathrm{R} 1$ and R2, respectively, are predicted to be ionized (MarvinSketch, ChemAxon). Indeed, in $\mathbf{1}$ the $\mathrm{p} K_{\mathrm{a}}$ values of the two 4-piperazinyl nitrogens are 7.44 (R1 substituent) and 8.12 (R2 substituent), whereas in 2 the corresponding numbers are 8.84 (R1 substituent, now a secondary amine) and 7.91 (R2 substituent, a tertiary amine). It is also worth noting that the previously described biological activity of a series of pyrazolo[3,4-c]pyridines including $\mathbf{1}$ and $\mathbf{2}$ as promising angiogenesis inhibitors was not correlated in terms of structure-activity relationships (SAR) with the CBS-inhibitory potential presented herein [52]. Indeed, the most potent CBS inhibitor $\mathbf{1}$ was shown to inhibit angiogenesis weakly, whereas 2 characterized by the presence of a 3-phenyl group was a very potent inhibitor of angiogenesis but a marginal inhibitor of CBS.

Table 1. The inhibitory activity of the 8 pyrazolo[3-c], pyridine derivatives against full length CBS. Percentage enzyme inhibition was measured at a final inhibitor concentration of $100 \mu \mathrm{M}$.

\begin{tabular}{|c|c|c|c|c|c|}
\hline Compound & R1 & R2 & R3 & R4 & Inhibition (\%) \\
\hline 1 & & & $\mathrm{H}$ & & 70 \\
\hline 2 & & & $\mathrm{H}$ & & 30 \\
\hline 3 & & & & & 20 \\
\hline 4 & & & $\mathrm{H}$ & & 20 \\
\hline 5 & & $\mathrm{~N} \equiv \mathrm{C}$ & & & No inhibition \\
\hline 6 & & & & $\mathrm{H}$ & No inhibition \\
\hline 7 & & $\mathrm{~N} \equiv \mathrm{C}$ & $\mathrm{H}$ & $\mathrm{H}$ & No inhibition \\
\hline 8 & & $\mathrm{Cl}$ & $\mathrm{H}$ & & $<20$ \\
\hline
\end{tabular}

In CBS the SAR observations and DSF results seem to favor a hypothesis where the active compounds bind CBS orthosterically and ligand ionization does not contribute to CBS binding through any direct interaction but, conversely, it opposes complex stabilization. Ionization can seriously impact activity either positively, by enhancing binding through charge-assisted hydrogen bonds and 
electrostatic contacts, or negatively by hindering affinity through repulsions or, more frequently, by the large desolvation penalties involved in ionic ligand binding. With the objective to further explore this scenario, a QSAR model was created by utilizing deep neural networks (DNN) and a dataset comprising the hereby reported and previously published CBS inhibitors (60 actives in total) and 613 inactives. The DNN was constructed using one input layer $(243 \times 673$ points), three hidden layers with 20 neurons each and an output layer with two neurons, namely [0 1] for actives compounds and [1 0] for non-active compounds. The learning workflow was stopped when at least $90 \%$ compounds from each group was correctly predicted. The final model resulted in 100\% success for active and $94 \%$ success for non-active compounds, values that render the prediction significant. The weighting factors between the input and the first hidden layers depict the significance of each descriptor to final decision. Extraction of descriptors with weighting factors greater than 0.8 demonstrated that the most important for group discrimination were those connected to lipophilicity, suggesting it as a key factor for efficient CBS inhibition. This proceeding was in excellent accordance with the hypothesis that the active pyrazolo[3,4-c]pyridine derivatives show a preference to bind CBS as non-ionized molecules. To provide additional strength to the hypothesis, molecular simulations of the interaction between 1 and CBS were undertaken. As previously mentioned, no crystal structure of human CBS has been described in complex with any inhibitor, either substrate-competitive or allosteric. Thus, at present the exact mode of action of known inhibitors is not unambiguously determined, whereas in several cases kinetic results are complex indicating that a mixed-mode inhibition may finally prevail [33]. In this study, in silico experiments were carried out in the catalytic site of the enzyme for estimating the validity regarding the competitive inhibition hypothesis in direct comparison with the SAR notions derived via in vitro screening and, further, for evaluating the contribution of each of the chemical functionalities present in $\mathbf{1}$ in CBS binding. For enhancing sampling accuracy, induced-fit flexible protein docking (IFD, Schrödinger LLC, New York, NY, USA, 2020) was applied on top-ranked binding geometries determined by rigid docking (Glide, Schrödinger LLC, New York, NY, USA, 2020) [55-58]. Overall, docking calculations showed that the dominant binding geometry of $\mathbf{1}$ would agree, yet not unambiguously, with the scenario that charge-assisted interactions are not necessary for efficient 1 binding to CBS (Figure 4). More specifically, the inhibitor binds CBS active site through a network of hydrogen bonds formed between the N1 pyrazole nitrogen of $\mathbf{1}$ and the side chain hydroxyl of T400, the 4-methoxybenzyl moiety at R4 of the inhibitor and side chain of K172, the phenylamino nitrogen at R2 and Y301, as well as the N4 of piperazine ring at position R1 and the side chain of Q222, whereas the complex is additionally stabilized by a strong $\pi-\pi$ stacking contact between the phenylamino ring at R4 and Y308. A clear SAR finding was that replacement of the aliphatic piperazine of R1 by an aromatic ring has a detrimental effect on activity, with the phenylamino analogues 5, 6 and 7 being inactive. The predicted binding geometry could account for this trend to a good extent. The aforementioned group is positioned in a solvent-exposed and highly polar area of the binding site where the existence of a hydrogen-bond acceptor could favor interaction with the water environment and stabilize the ligand through hydrogen bonds with adjacent polar residues E304 and S147. Moreover, the intramolecular interactions between R1 and R4 substituents are expected to influence free ligand energetics, with stronger stacking in the case of 5, 6 and 7 likely resulting to a shift toward conformations not favoring protein binding, while an R3 substitution bulkier that $\mathrm{H}$ seems unfavorable for CBS inhibition, as 3 carrying a phenyl group at this position retains only a fraction of the activity compared to the otherwise commonly substituted 1 . The presence of Lys172 in a close proximity to the bound inhibitor suggests that a coulombic repulsion between the ionic side chain of Lys172 and the positively charged state of the ligand could be a likely explanation for the increased $\mathrm{IC}_{50}$ obtained for $\mathbf{2}$, an analogue predicted to be slightly more basic than $\mathbf{1}$. It ought to be emphasized though that a less favorable interaction of the cationic form of $\mathbf{1}$ with the enzyme cannot be excluded. Thus, docking calculations using the IFD protocol and the protonated state of $\mathbf{1}$ have been performed as well and the most reasonable pose is depicted in Figure S1. Poses where the ligand does not occupy 
the inner side of CBS active site by a geometry which would permit contact of the inhibitor and PLP were not considered.

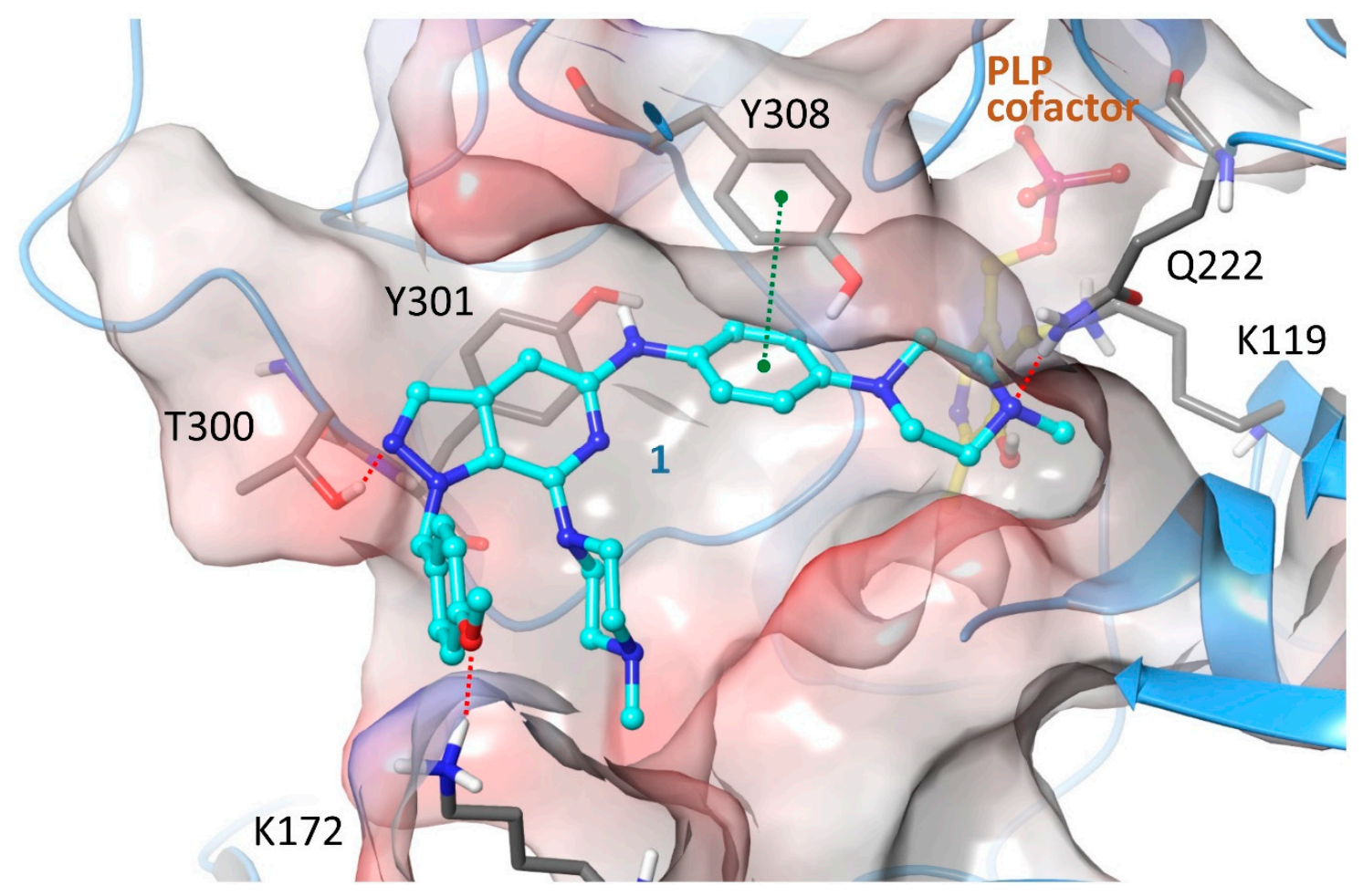

Figure 4. The dominant binding geometry of 1 inside the CBS active site as determined by the induced-fit algorithm for docking calculations. The inhibitor is anchored to the enzyme by a number of hydrogen bonds depicted as red dashed lines, whereas a strong stacking interaction between the phenylamino ring of 1 and Tyr308 (shown as green dashed line) further stabilizes the complex. The two piperazine rings of the inhibitor are deprotonated, whereas piperazine of $\mathrm{R} 2$ is positioned in close proximity to the catalytic Lys119, covalently attached in this structure to the cofactor pyridoxal aldehyde as a Schiff base. The protein is depicted as a blue ribbon and molecular surface colored according to the electrostatic potential (red: negative; blue: positive). The ligand and protein interaction geometry demonstrates high complementarity and an excellent occupancy of the pocket by the inhibitor.

To summarize, a rationally designed screen was devised for facilitating the exploration of biologically important subdomains in the chemical space that are represented by purine-like and pyrimidine-like heterocycles. This effort concluded in the discovery of a new scaffold with interesting CBS inhibitory properties. The active pyrazolopyridine analogue showed notable potency toward CBS, whereas a competitive inhibition mode was supported by biophysical analysis. The aforementioned activity was accompanied by moderate selectivity over the related enzyme CSE that is involved in sulfur metabolism as well and individually pursued as a drug target. While this selectivity seemed to be environmentally sensitive, it may provide a rationale and a structural basis for establishing CBS- or CSE-selective inhibition or concurrent CBS-CSE inhibition. Based on molecular simulations, fine-tuning of the ionization potential of the novel scaffold can possibly sustain the design of such enzyme-selective, optimized pyrazolopyridine-based inhibitors. Moreover, as the weak inhibitory properties of the discovered hit toward angiogenesis are likely not related to CBS inhibition, development of dual-specificity analogues seems to be a particularly promising perspective for this lead. To this end, the predictive aspect of the herein derived DNN model is expected to sustain optimization of the compound not only by guiding CBS activity enhancement, but also by rationalizing single- or dual-target specificity requisites. To this respect and in terms of chemistry, the pyrazolo[3,4-c]pyridine scaffold presented herein offers a versatile lead and a highly tractable 
starting point for developing optimized, biologically active molecules that are in perfect agreement with the principles of druglikeness.

\section{Materials and Methods}

\subsection{Expression and Purification of Full Length GST-CBS and His Tag-CBS Regulatory Domain}

Cystathionine beta synthase cDNA was cloned into the pGEX-Kg vector to create N-terminal GSH-S-Transferase (GST) fusion protein. For expression, E. coli expression cells (BL21 CodonPlus (DE3)) were transformed with the expression vector pGEX-Kg/GST-CBS. A fresh colony was chosen to grow a $5 \mathrm{~mL}$ starter culture in LB medium overnight at $37{ }^{\circ} \mathrm{C}$ and $180 \mathrm{rpm}$. All media were supplemented with $100 \mu \mathrm{g} / \mathrm{mL}$ ampicillin. The next day, the starter culture was transferred into $1 \mathrm{~L}$ of fresh LB medium containing $75 \mathrm{mg} / \mathrm{L}$ d-alanine, until cells reach an $\mathrm{OD}_{600}$ of 0.6. For induction, isopropyl-beta-D-thiogalactopyranoside (IPTG) was added to a final concentration of $0,1 \mathrm{mM}$. The culture was grown overnight at $30^{\circ} \mathrm{C}$ and $180 \mathrm{rpm}$. The cells were subsequently harvested at $6000 \times \mathrm{g}$ for $15 \mathrm{~min}$. After centrifugation, the cell pellet was resuspended in an ice-cold buffer containing $50 \mathrm{mM}$ Tris $\mathrm{pH}$ 8.0, $1 \mathrm{mM}$ EDTA, $25 \mathrm{mM}$ DTT, protease inhibitor, $1 \mathrm{mM}$ PMSF, Triton 0.5\%, $5 \mathrm{mM}$ PLP and $500 \mathrm{mM} \mathrm{NaCl}$. Cells were lysed by sonication on ice (sonication power $\sim 35 \%, 20 \mathrm{~s}$ pulse, $45 \mathrm{~s}$ pause for $20 \mathrm{~min}$ ). The cell extract was then centrifuged at $14,000 \times \mathrm{g}$ for $30 \mathrm{~min}$ at $4{ }^{\circ} \mathrm{C}$. After centrifugation, the soluble fraction containing GST-CBS was loaded onto a GSTrap FF $5 \mathrm{~mL}$ affinity column. The column was consecutively washed with five column volumes of binding buffer. The protein was eluted with five volume of elution buffer $50 \mathrm{mM}$ Tris-HCL, $10 \mathrm{mM}$ reduced GSH, $\mathrm{pH}$ 8.0. Fractions containing highly pure protein were pooled and immediately applied on anion exchange $\mathrm{Q}$ sepharose column fast flow. The column was washed with $20 \mathrm{mM}$ Phosphate buffer $\mathrm{pH}$ 8.0, $1 \mathrm{mM}$ EDTA and the bound proteins were eluted with a linear gradient of $\mathrm{NaCl}$ from 0 to $1.0 \mathrm{M}$ in the same buffer at a flow rate of $2 \mathrm{~mL} / \mathrm{min}$. The protein was further purified by gel filtration (Superose 6 prep. $20 \mathrm{mM}$ Phosphate buffer $\mathrm{pH}$ 8.0, $1 \mathrm{mM}$ EDTA, $500 \mathrm{mM} \mathrm{NaCl}$ and $10 \%$ glycerol) Finally, the GST-CBS protein samples were dialyzed and concentrated in $10 \mathrm{mM}$ Sodium Phosphate Buffer pH 8.2, DTT $1 \mathrm{mM}$ and glycerol 5\%. The purity of recombinant enzyme was checked by SDS-PAGE on $12 \%$ polyacrylamide gels. The regulatory CBS domain was expressed using the Addgene plasmid \#73238 and purified as previously described [30].

\subsection{Sample Preparation and Library Administration}

All tested samples were collected in powder and dissolved in 100\% DMSO. The stock solutions were prepared by the use of assay buffer $(50 \mathrm{mM}$ Sodium Phosphate $\mathrm{pH}$ 8.2) at a final DMSO concentration of $10 \%$. The structural and physicochemical assessment of the collection along with druggability analysis were performed by the use of Canvas software (Schrödinger LLC, New York, NY, USA, 2020).

\section{3. $\mathrm{H}_{2} \mathrm{~S}$ Detection Using the Methylene Blue Assay}

$\mathrm{H}_{2} \mathrm{~S}$ detection production was measured using the methylene blue colorimetric assay. To test the inhibitory effect of the compounds against CBS, samples were prepared in $100 \mu \mathrm{L}$ total volume containing $8 \mu \mathrm{g}$ of recombinant CBS, $1 \mathrm{mM}$ L-cysteine, $1 \mathrm{mM}$ homocysteine, $0.01 \mathrm{mM}$ PLP and $50 \mathrm{mM}$ sodium phosphate buffer $\mathrm{pH}$ 8.2. Initially, after sample preparation all samples were incubated at $37^{\circ} \mathrm{C}$ for $1 \mathrm{~h}$. After $60 \mathrm{~min}$, the samples were transferred on ice and $1 \%$ zinc acetate was added for trapping $\mathrm{H}_{2} \mathrm{~S}$, followed by the addition of $10 \%$ trichloroacetic acid for stopping the enzymatic reaction. Afterwards, freshly prepared solutions of $\mathrm{N}$, N-dimethyl-p-phenylenediamine-sulfate in $7.2 \mathrm{M} \mathrm{HCl}$ and $\mathrm{FeCl}_{3}$ in $1.2 \mathrm{M} \mathrm{HCl}$ were added followed by $15 \mathrm{~min}$ in the dark resulting in the formation of blue color. The sample solutions were transferred in transparent 96-well flat blank plates and the absorbance was measured at $650 \mathrm{~nm} . \mathrm{H}_{2} \mathrm{~S}$ quantification was carried out by a standard curve of $\mathrm{Na}_{2} \mathrm{~S}(0-250 \mu \mathrm{M})$. 


\section{4. $\mathrm{H}_{2} \mathrm{~S}$ Detection Using the 7-Azido-4-Methylcoumarin Assay}

Using $50 \mathrm{mM}$ Tris $\mathrm{HCl} \mathrm{pH} 8$ solution and black 96-well plate, $0.5 \mu \mathrm{g} /$ well of recombinant CBS was incubated $1 \mathrm{~h}$ at $37{ }^{\circ} \mathrm{C}$ in presence of various final concentrations of $\mathbf{1}$ in a total volume of $100 \mu \mathrm{L}$. CBS substrates were then added to reach $200 \mu \mathrm{L}$ total volume, $2 \mathrm{mM}$ L-cysteine, $2 \mathrm{mM}$ homocysteine, 0.005 mM PLP and 0.5 mM SAM, as well as the probe 7-azido-4-methylcoumarin (AzMC) (Sigma-Aldrich, Saint Louis, MO, USA) at a final concentration of $10 \mu \mathrm{M}(\mathrm{pH} 8.0)$. Fluorescence was measured in kinetic mode at $37^{\circ} \mathrm{C}$ with an Infinite 200 Pro reader (Tecan), with excitation and emission wavelengths of $365 \mathrm{~nm}$ and $450 \mathrm{~nm}$, respectively. The $\mathrm{IC}_{50}$ of the inhibitor was calculated using GraphPad Prism nonlinear fitting curve function.

\subsection{Differential Scanning Fluorimetry}

The regulatory domain of CBS was assayed at $2 \mu \mathrm{M}$ in a buffer consisting of $10 \mathrm{mM}$ HEPES at $\mathrm{pH} 7.8,150 \mathrm{mM} \mathrm{NaCl}$ and 10× SYPRO orange. Ligand concentrations of $10 \mu \mathrm{M}$ and $15 \mu \mathrm{M}$ were assessed, while all experiments were performed without SAM or in the presence of SAM at $100 \mu \mathrm{M}$ or $1 \mathrm{mM}$. The BioRad CFX-Connect RT-PCR instrument and white BioRad 96-well plates were utilized. Relative fluorescence intensities were measured by increasing the temperature from $25^{\circ} \mathrm{C}$ to $95^{\circ} \mathrm{C}$ at $0.5^{\circ} \mathrm{C} / \mathrm{min}$ and the melting curves along with $T_{\mathrm{m}}$ values were calculated by non-linear fitting of fluorescence units over temperature by using a four-parameter logistic function as provided in GraphPad Prism v. 7 software.

\subsection{Deep Neural Networks}

The Deep Neural Network (DNN) algorithm employed is back propagation (BP). The dataset was based on 673 compounds tested in vitro and was divided to two subsets. The first contained all molecules $(n=60)$ showing more than $50 \%$ inhibition, labeled as active compounds. The rest of molecules $(n=613)$ were labeled non-active compounds. Topological descriptors were calculated from the molecular descriptors workflow as implemented in Schrodinger Suite 2019. (Schrödinger LLC, New York, NY, USA, 2020). Initially 277 topological descriptors were predicted. All descriptors with zero values for all molecules were removed, reducing the final number to 243 . The values of each descriptor were normalized using the unit variance procedure. The training parameters for the DNN model were set as following: the number of hidden layers was 3; the number of neurons in each hidden layer was 20; the number of neurons in the output layer was 2, [1 0] for active compounds and [0 1] for non-active compounds; the activation and transfer functions were both sigmoid function; all weights of the network were initialized as random values; the number of iterations ranged from 1000 to 5000; during the gradient descent optimization procedure, the learning rate was 0.01 . All mathematical calculations were run using the software package MATLAB v2018b developed by MathWorks, USA (http://www.mathworks.com). The descriptors with greater importance were those connected with lipophilicity, partial equalization of orbital electronegativity, and connectivity indexes such as Balaban-type connectivity index J.

\subsection{Molecular Simulations}

The CBS crystal structure deposited under PDB code 1JBQ was selected and prepared for calculations, utilizing the Protein Preparation module of Maestro software (Schrödinger LLC, New York, NY, USA, 2020). The docking grid was prepared accordingly and centered manually around three reference points in the active site of CBS, namely the cofactor PLP and the two active site residues Tyr223 and Gly307. A stepwise workflow was followed, with rigid docking calculations (Glide SP algorithm, Schrödinger LLC, New York, NY, USA, 2020) deriving ensembles of low-energy binding geometries for the studied compounds and the induced-fit algorithm (IFD, Schrödinger LLC, New York, NY, USA, 2020) implemented for optimally exploring the exact binding site of the most interesting analogues in terms of a flexible protein representation. Marvin was used for drawing, displaying and characterizing chemical 
structures, substructures and reactions, Marvin v 17.13.0, 2017, ChemAxon (http://www.chemaxon.com). The assessment of ionization constants for the compounds was accomplished by MarvinSketch by using the macro mode and static prefix parameters and considering tautomerization and resonance.

\subsection{Statistical Analysis}

Statistics and graphs were created by the use of GraphPad Prism version 8.0. Evaluation and statistical analysis of in vitro screening experiments are represented as the means \pm SD. Furthermore, one-way ANOVA multiple comparison test was performed and $p$-values less than 0.05 were considered statistically significant.

Supplementary Materials: The Supplementary Materials are available online.

Author Contributions: Conceptualization, E.M. and A.P.; methodology, E.M., P.M. and A.P.; software, G.L.; validation, E.M., A.P., C.S. and V.M.; formal analysis, E.M., A.P., C.S. A.-M.F. and V.M.; investigation, A.-M.F., A.G., I.Z., F.A., N.L.; resources, E.M., A.P., C.S., N.P., C.E.V.; data curation, A.-M.F., A.G., I.Z., G.L., V.M., N.L.; writing—original draft preparation, E.M., A.P., V.M.; writing—review and editing, E.M., A.P., C.S., C.E.V., G.L.,V.M.; visualization, V.M.; supervision, E.M.; project administration, E.M., A.P., V.M.; funding acquisition, E.M. All authors have read and agreed to the published version of the manuscript.

Funding: This research is co-financed by Greece and the European Union (European Social Fund- ESF) through the Operational Programme «Human Resources Development, Education and Lifelong Learning» in the context of the project "Strengthening Human Resources Research Potential via Doctorate Research" (MIS-5000432), implemented by the State Scholarships Foundation-IK $\Upsilon$ (A.M.F.). We acknowledge support of this work by the project "INSPIRED" (MIS 5002550), under the Action "Reinforcement of the Research and Innovation Infrastructure", funded by the Operational Programme "Competitiveness, Entrepreneurship and Innovation" (NSRF 2014-2020) (E.M.). The APC were funded in the framework of a Stavros Niarchos Foundation (SNF) grant (I.Z.).

Conflicts of Interest: The authors declare no conflict of interest.

\section{References}

1. Wang, R. Physiological implications of hydrogen sulfide: A whiff exploration that blossomed. Physiol. Rev. 2012, 92, 791-896. [CrossRef] [PubMed]

2. Szabo, C.; Papapetropoulos, A. International Union of Basic and Clinical Pharmacology. CII: Pharmacological Modulation of $\mathrm{H}_{2} \mathrm{~S}$ Levels: $\mathrm{H}_{2} \mathrm{~S}$ Donors and H2S Biosynthesis Inhibitors. Pharmacol. Rev. 2017, 69, 497-564. [CrossRef] [PubMed]

3. Singh, S.; Banerjee, R. PLP-dependent $\mathrm{H}_{2} \mathrm{~S}$ biogenesis. Biochim. Biophys. Acta 2011, 1814, $1518-1527$. [CrossRef] [PubMed]

4. Banerjee, R.; Zou, C.G. Redox regulation and reaction mechanism of human cystathionine-beta-synthase: A PLP-dependent hemesensor protein. Arch. Biochem. Biophys. 2005, 433, 144-156. [CrossRef]

5. Zhang, J.Y.; Ding, Y.P.; Wang, Z.; Kong, Y.; Gao, R.; Chen, G. Hydrogen sulfide therapy in brain diseases: From bench to bedside. Med. Gas Res. 2017, 7, 113-119. [CrossRef]

6. Keller, R.; Chrastina, P.; Pavlíková, M.; Gouveia, S.; Ribes, A.; Kölker, S.; Blom, H.J.; Baumgartner, M.R.; Bártl, J.; Dionisi-Vici, C.; et al. Newborn screening for homocystinurias: Recent recommendations versus current practice. J. Inherit. Metab. Dis. 2019, 42, 128-139. [CrossRef]

7. Wen, Y.D.; Wang, H.; Zhu, Y.Z. The drug developments of hydrogen sulfide on cardiovascular disease. Oxidative Med. Cell. Longev. 2018, 2018, 4010395. [CrossRef]

8. Wu, D.; Si, W.; Wang, M.; Lv, S.; Ji, A.; Li, Y. Hydrogen sulfide in cancer: Friend or foe? Nitric Oxide Biol. Chem. 2015, 50, 38-45. [CrossRef]

9. Asimakopoulou, A.; Panopoulos, P.; Chasapis, C.T.; Coletta, C.; Zhou, Z.; Cirino, G.; Giannis, A.; Szabo, C.; Spyroulias, G.A.; Papapetropoulos, A. Selectivity of commonly used pharmacological inhibitors for cystathionine beta synthase (CBS) and cystathionine gamma lyase (CSE). Br. J. Pharmacol. 2013, 169, 922-932. [CrossRef] 
10. Druzhyna, N.; Szczesny, B.; Olah, G.; Módis, K.; Asimakopoulou, A.; Pavlidou, A.; Szoleczky, P.; Gerö, D.; Yanagi, K.; Törö, G.; et al. Screening of a composite library of clinically used drugs and well-characterized pharmacological compounds for cystathionine $\beta$-synthase inhibition identifies benserazide as a drug potentially suitable for repurposing for the experimental therapy of colon cancer. Pharmacol. Res. 2016, 113, 18-37. [CrossRef]

11. Hellmich, M.R.; Coletta, C.; Chao, C.; Szabo, C. The therapeutic potential of cystathionine beta-synthetase/hydrogen sulfide inhibition in cancer. Antioxid. Redox Signal. 2015, 22, 424-448. [CrossRef] [PubMed]

12. Panagaki, T.; Randi, E.B.; Augsburger, F.; Szabo, C. Overproduction of H(2)S, generated by CBS, inhibits mitochondrial Complex IV and suppresses oxidative phosphorylation in Down syndrome. Proc. Natl. Acad. Sci. USA 2019, 116, 18769-18771. [CrossRef] [PubMed]

13. Marechal, D.; Brault, V.; Leon, A.; Martin, D.; Lopes Pereira, P.; Loaëc, N.; Birling, M.-C.; Friocourt, G.; Blondel, M.; Herault, Y. Cbs overdosage is necessary and sufficient to induce cognitive phenotypes in mouse models of Down syndrome and interacts genetically with Dyrk1 $\alpha$. Hum. Mol. Genet. 2019, 28, 1561-1577. [CrossRef] [PubMed]

14. Gardiner, K.; Davisson, M. The sequence of human chromosome 21 and implications for research into Down syndrome. Genome Biol. 2000, 1, reviews0002.1. [CrossRef] [PubMed]

15. Skovby, F.; Krassikoff, N.; Francke, U. Assignment of the gene for cystathionine $\beta$-synthase to human chromosome 21 in somatic cell hybrids. Hum. Genet. 1984, 65, 291-294. [CrossRef] [PubMed]

16. Kamoun, P.P. Mental retardation in Down syndrome: Two ways to treat. Med. Hypotheses 2019, 131, 109289. [CrossRef]

17. Szabo, C. The re-emerging pathophysiological role of the cystathionine-beta-synthase-hydrogen sulfide system in Down syndrome. FEBS J. 2020. [CrossRef]

18. Bhattacharyya, S.; Saha, S.; Giri, K.; Lanza, I.R.; Nair, K.S.; Jennings, N.B.; Rodriguez-Aguayo, C.; Lopez-Berestein, G.; Basal, E.; Weaver, A.L.; et al. Cystathionine beta-synthase (CBS) contributes to advanced ovarian cancer progression and drug resistance. PLOS ONE 2013, 8, e79167. [CrossRef]

19. Kashfi, K. The dichotomous role of $\mathrm{H}_{2} \mathrm{~S}$ in cancer cell biology? Déjà vu all over again. Biochem. Pharmacol. 2018, 149, 205-223. [CrossRef]

20. Untereiner, A.A.; Pavlidou, A.; Druzhyna, N.; Papapetropoulos, A.; Hellmich, M.R.; Szabo, C. Drug resistance induces the upregulation of $\mathrm{H}_{2}$ S-producing enzymes in HCT116 colon cancer cells. Biochem. Pharmacol. 2018, 149, 174-185. [CrossRef]

21. Modis, K.; Coletta, C.; Asimakopoulou, A.; Szczesny, B.; Chao, C.; Papapetropoulos, A.; Hellmich, M.R.; Szabo, C. Effect of S-adenosyl-L-methionine (SAM), an allosteric activator of cystathionine-beta-synthase (CBS) on colorectal cancer cell proliferation and bioenergetics in vitro. Nitric Oxide Biol. Chem. 2014, 41, 146-156. [CrossRef] [PubMed]

22. Giuffrè, A.; Tomé, C.S.; Fernandes, D.G.F.; Zuhra, K.; Vicente, J.B. Hydrogen sulfide metabolism and signaling in the tumor microenvironment. Adv. Exp. Med. Biol. 2020, 1219, 335-353. [CrossRef] [PubMed]

23. Zuhra, K.; Augsburger, F.; Majtan, T.; Szabo, C. Cystathionine- $\beta$-synthase: Molecular regulation and pharmacological inhibition. Biomolecules 2020, 10, 697. [CrossRef] [PubMed]

24. Meier, M.; Janosik, M.; Kery, V.; Kraus, J.P.; Burkhard, P. Structure of human cystathionine beta-synthase: A unique pyridoxal 5'-phosphate-dependent heme protein. EMBO J. 2001, 20, 3910-3916. [CrossRef] [PubMed]

25. Ereno-Orbea, J.; Majtan, T.; Oyenarte, I.; Kraus, J.P.; Martinez-Cruz, L.A. Structural insight into the molecular mechanism of allosteric activation of human cystathionine beta-synthase by S-adenosylmethionine. Proc. Natl. Acad. Sci. USA 2014, 111, E3845-E3852. [CrossRef]

26. Pey, A.L.; Martinez-Cruz, L.A.; Kraus, J.P.; Majtan, T. Oligomeric status of human cystathionine beta-synthase modulates AdoMet binding. FEBS Lett. 2016, 590, 4461-4471. [CrossRef]

27. Ereno-Orbea, J.; Oyenarte, I.; Martinez-Cruz, L.A. CBS domains: Ligand binding sites and conformational variability. Arch. Biochem. Biophys. 2013, 540, 70-81. [CrossRef]

28. Catazaro, J.; Caprez, A.; Guru, A.; Swanson, D.; Powers, R. Functional evolution of PLP-dependent enzymes based on active-site structural similarities. Proteins Struct. Funct. Bioinform. 2014, 82, 2597-2608. [CrossRef] 
29. Koutmos, M.; Kabil, O.; Smith, J.L.; Banerjee, R. Structural basis for substrate activation and regulation by cystathionine beta-synthase (CBS) domains in cystathionine \{beta\}-synthase. Proc. Natl. Acad. Sci. USA 2010, 107, 20958-20963. [CrossRef]

30. McCorvie, T.J.; Kopec, J.; Hyung, S.J.; Fitzpatrick, F.; Feng, X.; Termine, D.; Strain-Damerell, C.; Vollmar, M.; Fleming, J.; Janz, J.M.; et al. Inter-domain communication of human cystathionine beta-synthase: Structural basis of S-adenosyl-L-methionine activation. J. Biol. Chem. 2014, 289, 36018-36030. [CrossRef]

31. Hnizda, A.; Spiwok, V.; Jurga, V.; Kozich, V.; Kodicek, M.; Kraus, J.P. Cross-talk between the catalytic core and the regulatory domain in cystathionine beta-synthase: Study by differential covalent labeling and computational modeling. Biochemistry 2010, 49, 10526-10534. [CrossRef] [PubMed]

32. Janošík, M.; Kery, V.; Gaustadnes, M.; Maclean, K.N.; Kraus, J.P. Regulation of human cystathionine $\beta$-synthase by S-adenosyl-1-methionine: evidence for two catalytically active conformations involving an autoinhibitory domain in the C-terminal region. Biochemistry 2001, 40, 10625-10633. [CrossRef] [PubMed]

33. Wang, L.; Cai, H.; Hu, Y.; Liu, F.; Huang, S.; Zhou, Y.; Yu, J.; Xu, J.; Wu, F. A pharmacological probe identifies cystathionine $\beta$-synthase as a new negative regulator for ferroptosis. Cell Death Dis. 2018, 9, 1005. [CrossRef] [PubMed]

34. Niu, W.; Chen, F.; Wang, J.; Qian, J.; Yan, S. Antitumor effect of sikokianin C, a selective cystathionine $\beta$-synthase inhibitor, against human colon cancer in vitro and in vivo. MedChemComm 2018, 9, 113-120. [CrossRef]

35. Niu, W.; Wu, P.; Chen, F.; Wang, J.; Shang, X.; Xu, C. Discovery of selective cystathionine $\beta$-synthase inhibitors by high-throughput screening with a fluorescent thiol probe. MedChem Comm 2017, 8, 198-201. [CrossRef]

36. Zuhra, K.; Sousa, P.M.F.; Paulini, G.; Lemos, A.R.; Kalme, Z.; Bisenieks, I.; Bisenieks, E.; Vigante, B.; Duburs, G.; Bandeiras, T.M.; et al. Screening pyridine derivatives against human hydrogen sulfide-synthesizing enzymes by orthogonal methods. Sci. Rep. 2019, 9, 684. [CrossRef]

37. Nakai, T.; Nakagawa, N.; Maoka, N.; Masui, R.; Kuramitsu, S.; Kamiya, N. Structure of P-protein of the glycine cleavage system: Implications for nonketotic hyperglycinemia. EMBO J. 2005, 24, 1523-1536. [CrossRef]

38. Macarron, R.; Banks, M.N.; Bojanic, D.; Burns, D.J.; Cirovic, D.A.; Garyantes, T.; Green, D.V.; Hertzberg, R.P.; Janzen, W.P.; Paslay, J.W.; et al. Impact of high-throughput screening in biomedical research. Nat. Rev. Drug Discov. 2011, 10, 188-195. [CrossRef]

39. Friesner, R.A.; Banks, J.L.; Murphy, R.B.; Halgren, T.A.; Klicic, J.J.; Mainz, D.T.; Repasky, M.P.; Knoll, E.H.; Shelley, M.; Perry, J.K.; et al. Glide: A new approach for rapid, accurate docking and scoring. 1. Method and assessment of docking accuracy. J. Med. Chem. 2004, 47, 1739-1749. [CrossRef]

40. Friesner, R.A.; Murphy, R.B.; Repasky, M.P.; Frye, L.L.; Greenwood, J.R.; Halgren, T.A.; Sanschagrin, P.C.; Mainz, D.T. Extra precision Glide: Docking and scoring incorporating a model of hydrophobic enclosure for protein-ligand complexes. J. Med. Chem. 2006, 49, 6177-6196. [CrossRef]

41. Halgren, T.A.; Murphy, R.B.; Friesner, R.A.; Beard, H.S.; Frye, L.L.; Pollard, W.T.; Banks, J.L. Glide: A new approach for rapid, accurate docking and scoring. 2. Enrichment factors in database screening. J. Med. Chem. 2004, 47, 1750-1759. [CrossRef] [PubMed]

42. Duan, J.; Dixon, S.L.; Lowrie, J.F.; Sherman, W. Analysis and comparison of 2D fingerprints: Insights into database screening performance using eight fingerprint methods. J. Mol. Graph. Model. 2010, 29, 157-170. [CrossRef] [PubMed]

43. Sastry, M.; Lowrie, J.F.; Dixon, S.L.; Sherman, W. Large-scale systematic analysis of 2D fingerprint methods and parameters to improve virtual screening enrichments. J. Chem. Inf. Model. 2010, 50, 771-784. [CrossRef] [PubMed]

44. Bukovska, G.; Kery, V.; Kraus, J.P. Expression of human cystathionine beta-synthase in Escherichia coli: Purification and characterization. Protein Expr. Purif. 1994, 5, 442-448. [CrossRef]

45. Frank, N.; Kent, J.O.; Meier, M.; Kraus, J.P. Purification and characterization of the wild type and truncated human cystathionine beta-synthase enzymes expressed in E. coli. Arch. Biochem. Biophys. 2008, 470, 64-72. [CrossRef]

46. Kraus, J.; Packman, S.; Fowler, B.; Rosenberg, L.E. Purification and properties of cystathionine beta-synthase from human liver. Evidence for identical subunits. J. Biol. Chem. 1978, 253, 6523-6528.

47. Oyenarte, I.; Majtan, T.; Ereno, J.; Corral-Rodriguez, M.A.; Kraus, J.P.; Martinez-Cruz, L.A. Purification, crystallization and preliminary crystallographic analysis of human cystathionine beta-synthase. Acta Crystallogr. Sect. F Struct. Biol. Cryst. Commun. 2012, 68, 1318-1322. [CrossRef] 
48. Wingfield, P.T. Overview of the purification of recombinant proteins. Curr. Protoc. Protein Sci. 2015, 80, 6.1.1-6.1.35. [CrossRef]

49. Moest, R.R. Hydrogen sulfide determination by the methylene blue method. Anal. Chem. 1975, 47, $1204-1205$. [CrossRef]

50. Reese, B.K.; Finneran, D.W.; Mills, H.J.; Zhu, M.-X.; Morse, J.W. Examination and refinement of the determination of aqueous hydrogen sulfide by the methylene blue method. Aquat. Geochem. 2011, 17, 567-582. [CrossRef]

51. Hartle, M.D.; Pluth, M.D. A practical guide to working with $\mathrm{H}_{2} \mathrm{~S}$ at the interface of chemistry and biology. Chem. Soc. Rev. 2016, 45, 6108-6117. [CrossRef] [PubMed]

52. Michailidou, M.; Giannouli, V.; Kotsikoris, V.; Papadodima, O.; Kontogianni, G.; Kostakis, I.K.; Lougiakis, N.; Chatziioannou, A.; Kolisis, F.N.; Marakos, P.; et al. Novel pyrazolopyridine derivatives as potential angiogenesis inhibitors: Synthesis, biological evaluation and transcriptome-based mechanistic analysis. Eur. J. Med. Chem. 2016, 121, 143-157. [CrossRef] [PubMed]

53. Augsburger, F.; Randi, E.B.; Jendly, M.; Ascencao, K.; Dilek, N.; Szabo, C. Role of 3-mercaptopyruvate sulfurtransferase in the regulation of proliferation, migration, and bioenergetics in murine colon cancer cells. Biomolecules 2020, 10, 447. [CrossRef] [PubMed]

54. Niesen, F.H.; Berglund, H.; Vedadi, M. The use of differential scanning fluorimetry to detect ligand interactions that promote protein stability. Nat. Protocols 2007, 2, 2212-2221. [CrossRef]

55. Farid, R.; Day, T.; Friesner, R.A.; Pearlstein, R.A. New insights about HERG blockade obtained from protein modeling, potential energy mapping, and docking studies. Bioorganic Med. Chem. 2006, 14, 3160-3173. [CrossRef]

56. Sherman, W.; Beard, H.S.; Farid, R. Use of an induced fit receptor structure in virtual screening. Chem. Biol. Drug Des. 2006, 67, 83-84. [CrossRef]

57. Sherman, W.; Day, T.; Jacobson, M.P.; Friesner, R.A.; Farid, R. Novel procedure for modeling ligand/receptor induced fit effects. J. Med. Chem. 2006, 49, 534-553. [CrossRef]

58. Botou, M.; Yalelis, V.; Lazou, P.; Zantza, I.; Papakostas, K.; Charalambous, V.; Mikros, E.; Flemetakis, E.; Frillingos, S. Specificity profile of NAT/NCS2 purine transporters in Sinorhizobium (Ensifer) meliloti. Mol. Microbiol. 2020. [CrossRef]

Sample Availability: Samples of the compounds 1, 3, 4, 5 and 7 are available $(\leq 1 \mathrm{mg})$ from the authors.

(C) 2020 by the authors. Licensee MDPI, Basel, Switzerland. This article is an open access article distributed under the terms and conditions of the Creative Commons Attribution (CC BY) license (http://creativecommons.org/licenses/by/4.0/). 